J Am Acad Dermatol. 2009 July ; 61(1): 1-16. doi:10.1016/j.jaad.2008.12.051.

\title{
Neurofibromatosis type 1
}

Kevin P. Boyd, MD, Bruce R. Korf, MD, PhD, and Amy Theos, MD* University of Birmingham at Alabama, Department of Dermatology, EFH 414, 1530 3rd Ave S, Birmingham, AL 35294-0009, Business: 205-934-5188, Fax: 205-934-5766, E-mail: amy.theos@chsys.org

\section{Abstract}

Neurofibromatosis type 1 (NF1) is an autosomal dominant, multisystem disorder affecting approximately 1 in 3500 people. Significant advances in the understanding of the pathophysiology of NF1 have been made in the last decade. While no medical therapies are currently available, trials are ongoing to discover and test medical treatments for the various manifestations of NF1, primarily plexiform neurofibromas, learning disabilities, and optic pathway gliomas. Additionally, mutational analysis has become available on a clinical basis and is useful for diagnostic confirmation in individuals who do not fulfill diagnostic criteria or when prenatal diagnosis is desired. There are several disorders which may share overlapping features with NF1; in 2007, a disorder with cutaneous findings similar to NF1 was described. This paper addresses the dermatologist's role in diagnosis and management of NF1 and describes the variety of cutaneous and extracutaneous findings in NF1 to which the dermatologist may be exposed.

\section{Keywords}

neurofibromatosis type 1; cafe-au-lait macule; SPRED1; neurofibroma

\section{Introduction}

Neurofibromatosis type 1 (NF1) is an autosomal dominant, multisystem disorder affecting approximately 1 in 3500 people. The earliest historical evidence first appeared in the $13^{\text {th }}$ century but it wasn't until Friedrich Daniel von Recklinghausen published his landmark paper (in German) On the Multiple Fibromas of the Skin and Their Relationship to the Multiple Neuromas in 1882 that neurofibromatosis began gaining recognition as a distinct disorder. More recently, in 1956 Crowe, Schull, \& Neel published a milestone manuscript detailing the numerous manifestations of this disorder ${ }^{1}$.

In 1982, Riccardi classified the heterogeneous neurofibromatosis disorders into eight categories $^{2}$. These have not been universally-accepted, although several persist. Neurofibromatosis type I and II have remained as originally classified. NF II results from a mutation in the NF2 gene and is characterized by bilateral vestibular schwannomas and various other tumors. NF VII is now referred to as schwannomatosis and is distinguished by the late-

\footnotetext{
* To whom correspondence and reprint requests should be sent, Dr. Amy Theos, MD, University of Alabama at Birmingham. Conflict of Interest Disclosure: None declared

CME Learning Objectives: Following this activity, the participant will be able to: 1) discuss the indications and limitations of genetic testing in NF1, 2) distinguish common and uncommon cutaneous findings, 3) and recognize the dermatologist's role in diagnosis and management.

Capsule summary: Many advances have increased our ability to understand and diagnose neurofibromatosis type 1 . This paper will review current thinking on the pathogenesis, discuss the visible manifestations, and describe a methodical approach to diagnosis.
} 
onset of multiple schwannomas and the absence of features of classic NF I or NF II. These tumors cause significant pain for the patient and can occur on spinal, cranial, or peripheral nerves. Segmental NF I and familial café-au-lait spots have replaced NF V and NF VI, respectively, and are discussed in more detail in a later section. NF III, IV, and VIII described variant, atypical, and "not otherwise specified" forms; these are not routinely used in clinical practice.

Significant advances in the understanding of the pathophysiology of NF1 have been made in the last decade and this article will highlight those advances which affect our care of patients with NF1. Since the NF1 gene was discovered in $1990^{3}$, mutational analysis has become available on a clinical basis and is useful for diagnostic confirmation in individuals who do not fulfill diagnostic criteria or when prenatal diagnosis is desired. While no medical therapies are currently available, trials are ongoing to discover and test medical treatments for the various manifestations of NF1, primarily plexiform neurofibromas, learning disabilities, and optic pathway gliomas, which are a significant cause of morbidity in these patients. In 2007, a disorder with cutaneous findings (multiple café-au-lait macules and axillary freckling) similar to NF1 was described ${ }^{4}$, although the causative gene (SPREDI) was different.

\section{Genetics of NF1}

\section{Inheritance}

NF1 is an autosomal dominant disorder, with a nearly even split between spontaneous and inherited mutations. Penetrance approaches $100 \%$ by age 20 ; if the patient has the mutation, he or she will exhibit manifestations, although expressivity is highly variable, even among family members with the same mutation ${ }^{5,6}$. This point is important for genetic counseling, because an individual with mild clinical findings can have a child with a more severe phenotype, or vice versa.

\section{NF1 Gene}

The NF1 gene is located on chromosome 17q11.2 and encodes for the protein neurofibromin. This large gene (60 exons and $>300$ kilobases $(\mathrm{kb})$ of genomic DNA) has one of the highest rates of spontaneous mutations in the entire human genome ${ }^{7}$. Accordingly, the types of mutations that cause the NF1 phenotype vary from complete gene deletions, insertions, stop, and splicing mutations. Other variations include amino acid substitutions and chromosomal rearrangements ${ }^{8}$. In a study of 189 patients with known germline mutations, 85 had a recurrent mutation ${ }^{9}$; another study found that most lead to premature termination of translation of the gene product ${ }^{10}$.

\section{Mosaicism}

Mosaicism describes an individual with two genetically distinct cell lines as a result of a postzygotic gene mutation. NF1 occurs in mosaic forms that are classified as segmental, generalized, or gonadal ${ }^{11}$. Individuals with segmental involvement may have regions of pigmentary alterations, tumor growths, or both manifestations that are restricted to one or more body segments. Generalized mosaics appear clinically similar to nonmosaic cases but have little to no evidence of the disorder when the blood leukocytes are screened for the NF1 gene mutation. Gonadal is the rarest type and occurs when only the ova or sperm are affected. This is suspected if two or more children of otherwise unaffected parents develop the disorder ${ }^{12}$.

The risk of transmission of NF1 from patients with segmental involvement is unknown, but case reports of such transmission exist; the parents presumably having involvement of gonadal tissue. Consoli et al confirmed a case of gonadal mosaicism in a patient previously presented ${ }^{13-17}$. The visibly-affected areas in segmental patients need not cover the genitalia to 
confer risk of transmission, a fact which is important for counseling ${ }^{11}$. There are even some cases of segmental NF1 apparently being "transmitted" to offspring; the mechanism (if one exists) behind this is unclear ${ }^{16,18}$. One case reports exists of a 29 -year old man with clear evidence of segmental NF1 whose parents and siblings exhibited no evidence of NF1 but whose maternal aunt, cousin, and $2^{\text {nd }}$ cousin had classic $\mathrm{NF}^{19}$. It is possible that this represents two independent NF1 mutations in the two branches of the family, though that was not tested in the published data.

\section{Pathogenesis of NF1}

Neurofibromin, the $N F 1$ gene protein product, is a tumor suppressor expressed in many cells, primarily in neurons, glial, Schwann cells and early in melanocyte development ${ }^{20}$. This protein is a regulator of ras guanosine triphosphatase activity (GTPase-activating protein, GAP) and as such serves as a regulator of signals for cell proliferation and differentiation ${ }^{5}$. (Figure 1). The loss of function of neurofibromin may therefore remove this regulation, and lead to uncontrolled cell proliferation. Schwann cells in neurofibromas, and melanocytes in café-aulait macules have a mutation in both $N F 1$ alleles, including a germline and an acquired somatic mutation and are considered the primary tumor cell in their respective cutaneous manifestation. Based on these findings, it is likely that NF1 functions as a tumor suppressor gene ${ }^{21,22}$. Both of these cell types are descendants of neural crest. The exact timing of the acquired mutation is unknown but is crucial in the development of the various manifestations; experiments have shown that NFI gene inactivation at the neural crest stage and mature Schwann cell stage do not lead to tumor formation. However, in a progenitor intermediate step between these two stages, tumor formation occurs with $N F 1$ gene inactivation ${ }^{23}$.

\section{Diagnosis}

\section{Diagnostic Criteria}

In 1987, seven cardinal diagnostic criteria for NF1 were established, two of which must be met in order to diagnose an individual with NF1. (Figure 2). These diagnostic criteria have been shown to be both highly specific and sensitive for adults with $\mathrm{NF}^{24}$. Because some of the criteria may not manifest until later in life, they are not as sensitive in children, especially those under the age of 8 . A 2000 retrospective review of nearly 1900 cases of NF1 found that $46 \%$ of sporadic cases did not meet criteria by age 1 ; however, $97 \%$ met criteria by age 8 , and all fulfilled them by age $20^{25}$.

The diagnosis of NF1 is generally straightforward when one follows the NIH guidelines; however, patients with these classic findings may not first present to a dermatologist. Of particular interest to dermatologists is the approach to diagnosis of a patient who has some features of NF1 but fails to fully meet diagnostic criteria. A diagnostic algorithm geared towards the dermatologist is provided in Figure 2. Further, it is important to recognize key historical or physical findings that may require - beyond a referral to genetics - a timely consultation with varying specialties including orthopedics, ophthalmology, or neurology.

\section{Genetic Testing}

Recently molecular testing for NF1 has become clinically available. Because of the large size of the $N F 1$ gene and the lack of mutation hotspots, a multi-step detection protocol is preferred. A comprehensive screening approach to the $N F 1$ gene found mutations in greater than $95 \%$ of tested subjects (including both spontaneous and inherited mutations) fulfilling NIH diagnostic criteria $^{8}$. This comprehensive approach begins with an optimized protein truncation test, followed by FISH analysis, direct sequencing, long-range RT-PCR with Southern blot analysis, and/or cytogenetic analysis, if necessary, and is utilized in only a select few laboratories (http://www.genetests.org; August 13, 2008). Molecular testing is not indicated for the routine 
clinical care of patients with NF1, but can be helpful in individuals suspected of having NF1 (e.g. a young child with multiple café-au-lait spots and unaffected parents or a patient with a single criterion) or when prenatal or preimplantation genetic diagnosis is desired (Table III). Some experts are calling for a revision of the 1987 criteria to include a positive molecular test as a definitive, stand-alone diagnostic criterion.

A limitation of genetic testing is the lack of genotype-phenotype correlations. Therefore, while useful for diagnostic confirmation, a positive test will not predict disease severity or outcome. However, there are two exceptions. The first results from complete loss of the $N F 1$ gene along with multiple contiguous genes and occurs in $4-5 \%$ of patients with NF1 ${ }^{26}$. Patients with whole gene deletion present with a very large neurofibroma burden, more severe cognitive impairment, large hands and feet, dysmorphic facial features, and have a higher lifetime risk of developing malignant peripheral nerve sheath tumors (MPNST) ${ }^{27,28}$. A 3-base pair inframe deletion in exon 17 of the NFl gene is the second exception. Patients with this genetic mutation have an absence of cutaneous neurofibromas and appear to have a lower incidence of serious complications ${ }^{29}$.

\section{Differential Diagnosis}

NF1-Like Syndrome: An important disorder to distinguish from NF1 is NF1-like syndrome. This disorder, first described in 2007, consists primarily of multiple café-au-lait macules, axillary freckling, and macrocephaly ${ }^{4}$. Comprehensive mutational analysis for the $N F 1$ gene was performed on affected individuals from five families; all were negative. Through genome linkage studies, they localized the disorder to chromosome 15 and, based on disease distribution within the families, determined that it was autosomal dominant. The responsible gene is $S P R E D 1$, which is involved in RAS-MAPK (mitogen-activated protein kinase) regulation, similar to neurofibromin (Figure 1). Lipomas, Noonan-like facies, learning and behavioral problems were present in some of the families; however, it was uncertain how these findings were related to the genetic alteration ${ }^{4}$. This disorder warrants further study to better characterize its phenotype and distinguish it from NF1. At publication, clinical testing for this disorder was available only at two laboratories in the United States. (http://www.genetests.org; October 20, 2008). NF1-like syndrome should be suspected in families in which individuals present with multiple café-au-lait macules, but without Lisch nodules, neurofibromas, and NF1 gene abnormalities.

Familial Café-au Lait Spots (FCALS): Familial café-au-lait spots is a disorder with an uncertain relationship to NF1. Riccardi described two families whose affected members had only multiple café-au-lait macules (CALMs) and felt that they represented a disorder that was separate from the classic form ${ }^{30}$. Affected individuals do not develop other manifestations of NF1. It segregates as an autosomal dominant disorder and there are conflicting results on whether FCALS is linked to NF1 ${ }^{31,32}$. Charrow et al contended that it was a separate entity and should be treated as such. It does not appear to confer any increased risk of developing classical NF1.

Segmental NF1: As mentioned previously, NF1 can manifest as a mosaic (segmental) disorder in both localized and generalized forms. Localized, segmental neurofibromatosis should be considered when skin findings are localized to a particular area of the skin and there is no family history (Figures $3 \mathrm{a} \& \mathrm{~b}$ ). This is in contrast to FCALS, wherein there is often a family history of "multiple birthmarks" and the sole finding is that of CALMs. Testing of lesional tissue (neurofibromas, café-au-lait macules) is available and is of particular use in these patients. Maertens et al. tested lesional tissue in three patients with segmental NF1, each of which had different skin manifestations (pigmentary alone, tumor alone, and a combination of both). Through comprehensive testing, mutations were found in all affected cells; biallelic 
inactivation was found in either the Schwann cells of neurofibromas or in the melanocytes of $\mathrm{CALMs}^{21}$. These three cases illustrate not only the variability of the phenotypic expression of NF1 but also the ability to reliably test lesional tissue for the NF1 mutation if the diagnosis is uncertain. In 2001, Ruggieri and Huson classified the various types of mosaic NF1 into pigmentary changes alone (background hyperpigmentation, CALMs, freckling), neurofibromas alone, both pigmentary and neurofibromas, and isolated plexiform neurofibromas ${ }^{11}$.

Other diagnostic considerations are given in Figure 2 and will not be discussed in detail here.

\section{Cutaneous Manifestations}

Dermatologists should quickly recognize not only the salient skin features but also the less common cutaneous findings, as these latter aspects may be the source of a referral. A listing of the common and uncommon cutaneous features is provided in Table I. The following is a brief explanation of these findings. Additional detail is provided on the more rare skin manifestations as well as non-cutaneous findings that are easy to detect on physical examination or history.

\section{Pigmentary}

Café-au-lait Macules-The café-au-lait macule is one of the seven cardinal diagnostic criteria of NF1 (Figure 4). The classic lesion is well-demarcated with smooth borders ("coast of California") and homogeneous in appearance. Generally, the color is close to that of its namesake but can range from tan to dark brown. To fulfill this requirement, patients need six or more $>5 \mathrm{~mm}$ (pre-puberty) or $>15 \mathrm{~mm}$ (post-puberty). Less than $1 \%$ of children under 5 without NF1 have more than two; when multiple are present this is highly suggestive of $\mathrm{NF}^{33}$. The prevalence of CALMs in the general population has varied between 3 to $36 \%$ depending on the population studied but the presence of multiple CALMs in an otherwise normal population is generally less than $1 \%^{34}$. The CALM is frequently the first sign, occurring in $99 \%$ of NF1 patients within first year of life ${ }^{25}$. Patients continue to accrue them throughout childhood but they often fade in adulthood.

CALMs get their pigment from the melanocyte, which has been shown to have an increased concentration of melanin and giant melanosomes (macromelanosomes or melanin macroglobules); however, the absolute number of melanocytes in a non-NF1 CALM relative to the surrounding normal skin is not greater ${ }^{35}$. In NF1 patients, it has been shown that their CALMs have an increased number of melanocytes, although there is still some debate on this issue $^{36}$. Others have demonstrated at the organelle level an even greater concentration of melanin and macromelanosomes in both CALM and non-CALM skin when compared to non$\mathrm{NF} 1$ skin controls ${ }^{37}$. Recent investigations have found that the melanocyte in the CALM has a mutation in both copies of the NF1 gene and that the melanocytes of non-CALM NF1 skin show the germline mutation only 22 .

Skinfold Freckling-Skinfold freckling (Crowe's sign) is the most specific of the cardinal criteria for NF1 (Figure 5). It is considered nearly pathognomonic. It is second only to CALMs in terms of age-related frequency ${ }^{24}$ and generally occurs between the ages of 3 and 5 in either the axillae and/or groin ${ }^{38}$; a majority of adults have the freckling $(\sim 90 \%)^{39}$. Other sites include under the neck and breasts, around the lips, and even the trunk of adults; however, none of these fulfill the NIH diagnostic criterion. Their appearance is similar to that of solar-induced freckling but, notably, these occur almost exclusively in areas with minimal to no sun exposure. Their size ranges from 1-3 mm, distinguishing them from CALMs. The cause of these lesions is unknown but it has been suggested that they might be due to the increased friction, temperature, and/or moisture inherent to these areas ${ }^{40,41}$. 
Generalized Hyperpigmentation-Also noted (although not extensively studied) is a generalized, hyperpigmentation in NF1 patients when compared to their unaffected parents or siblings. Interestingly, the involved body regions of patients with segmental NF1 often have a background of hyperpigmentation that is sharply demarcated from the uninvolved skin (Figure 3a). Melanocytes from the hyperpigmented skin have a one-hit mutation whereas those from the overlying CALMS have two-hits ${ }^{21}$. This strongly suggests that in the patient with nonsegmental NF1, the observed globally-increased pigmentation is likely due to the one-hit mutation in the melanocytes.

\section{Tumor}

Cutaneous Neurofibromas-The neurofibroma is considered another one of the hallmark signs of NF1 (Figures $6 a \& b$ ). Neurofibromas can occur anywhere on the body and there is a wide variation in their shape and size. Terminology has varied and, at times, been somewhat confusing. Generally, the "cutaneous" or "dermal" tumors are dome-shaped, soft, fleshy, and skin-color to slightly hyperpigmented and "subcutaneous" are a firm, nodular variety.

Cutaneous neurofibromas usually do not become apparent until puberty and may continue to increase in size and number throughout adulthood. Outside of puberty, pregnancy is the other major time associated with increased growth. The neurofibroma is a major source of morbidity in these patients due to the sheer number, visibility, and size of these tumors ${ }^{42}$.

The tumors themselves are comprised of Schwann cells, fibroblasts, mast cells, and perineural cells. There is also an admixture of collagen and extracelullar matrix. Analogously to melanocytes, the neurofibroma-derived Schwann cell - believed to be the primary tumor cell in neurofibromas - has been shown to have both a germline and second-hit mutation in the $N F 1$ gene, the latter of these differing in each tumor in a patient ${ }^{43}$. Both Schwann cells and melanocytes share a common heritage in the neural crest and may be derived from a bipotent glial-melanocytic precursor ${ }^{21}$.

Blue-Red and Pseudoatrophic Macules-The blue-red macule (BRM) and pseudoatrophic macule (PAM) may represent unusual variants of cutaneous neurofibromas. In one case report, the BRM was described as soft to palpation, ill-defined, and appearing primarily on the trunk ${ }^{44}$. They appeared prior to or during puberty and became slightly elevated or dome shaped with time. Histopathologic examination reveals an increased number of thickened blood vessel walls with widened lumina and tumorlike neurogenic tissue in the papillary and reticular dermis. The source of their red color is clear; when hemostasis occurs in these lesions they develop a bluish-tint. A more recent report noted the presence of BRMs in 44 out of 583 patients, primarily on the trunk. Histologically, the thickened vessel walls were attributed to neurofibromatous tissue infiltration. They proposed that the blue-red macule may be considered an unusual variety of neurofibroma and, thus, sufficient for meeting a diagnostic criterion of $\mathrm{NF}^{45}$.

In the same 1982 report $^{44}$, pseudoatrophic macules were described as oval, slightly depressed lesions ranging in size from $5-10 \mathrm{~cm}$. Skin texture and color were similar relative to surrounding skin, although upon palpation the lesions were "softer" and showed a loss of underlying subcutaneous tissue. Histologic examination showed a reduction in collagen in the reticular dermis and increased perivascularly-situated neuroid tissue with Schwann cells and fibroblasts. Another case report from 1996 had similar clinical features; histologic examination revealed replacement of collagen bundles with neuroid tissue, consisting of neoplastic cells with oval/spindle nuclei ${ }^{46}$. Norris et al. examined the ultrastructure of biopsies of these lesions (they referred to them as neurofibromatous dermal hypoplasia or $\mathrm{NDH}$ ) as well as the response to several vasodilators and a vasoconstrictor. Histologic examination showed loose whorls of neurofibromatous tissue intermingled with collagen fibers surrounding both nerve trunks and 
small blood vessels; the primary cell type was the perineurial cell. Further, the authors postulated that the cuff of cells surrounding the vessels acted as both a physical splint and diffusion barrier because the pseudo-atrophic macules did not respond with a wheal and flare response to vasodilators ${ }^{47}$. It is interesting to note that in both the blue-red and pseudo-atrophic macules, there is a similarity in that neurofibromatous tissue surrounds (PAMs) or infiltrates (BRMs) vascular structures, leading to their unique clinical appearances.

Plexiform Neurofibroma-The plexiform neurofibroma ( $\mathrm{PN})$ is distinct from the cutaneous neurofibroma in that it is usually congenital. Superficial PNs are often associated with overlying hyperpigmentation and/or hypertrichosis and may be easily confused with a congenital melanocytic nevus (Figure 7). The affected skin may also appear thickened. These tumors are diffuse, growing along the length of a nerve and feel like a "bag of worms". PN can be quite disfiguring and may interfere with growth and function of the affected area. Eight to twelve percent of NF1 patients will develop a malignant peripheral nerve sheath tumor, and usually these arise from pre-existing plexiform neurofibromas ${ }^{48,49}$. A warning sign is the development of persistent pain or rapid growth in an otherwise stable PN.

\section{Other Cutaneous Findings}

Juvenile Xanthogranuloma-The purported triple association of juvenile xanthogranuloma (JXG), NF1, and juvenile myelomonocytic leukemia (JMML) is often reported and the source of frequent debate. In 1990, Morier et al. reported on their own case and reviewed the literature, finding an additional 23 cases $^{50}$. An analysis in 1995 found that the risk of JMML in patients with NF1 and JXG was 20-32x higher than in other patients with $\mathrm{NF} 1$, although the methodology of this analysis has been called into question ${ }^{51,52}$. In their commentary, Burgdorf et al. analyzed the literature and all available information pertaining to the association and found that patients with NF1 are, indeed, at an increased risk of developing JMML and JXG but the triple association of these findings (assuming the worst odds) is less than $1 \%$ per year; however, regardless of the presence of JXGs, children with NF1 are at a 200 to 500-fold greater risk of this hematologic malignancy ${ }^{53}$. Their conclusion was that physicians should be aware of presenting features of JMML (hepatosplenomegaly, lymphadenopathy, pallor, petechiae), but routine screening in patients with NF1 is of no benefit. JXGs in children with JMML most often present as multiple papules or nodules no larger than $1 \mathrm{~cm}$ or as confluent papular lesions. ${ }^{54}$.

Glomus Tumor-The glomus tumor is derived from the glomus body, which is a specialized vascular structure involved in thermoregulation. Clinically, the tumor appears as a small bluered papule or nodule, is characterized by marked pain and cold intolerance, and is most commonly seen in the subungual region of the finger ${ }^{55}$. The finding of multiple glomus tumors in one individual is rare in the general population but seven case reports exist in NF1 patients ${ }^{56-58}$. De Smet et al postulate that the glomus cell is of neural crest origin and, much like the Schwann cell in neurofibromas, is the tumor cell in glomus tumors. A similar two-hit mechanism that has been described in both neurofibroma-derived Schwann cells and CALMderived melanocytes could explain the increased frequency of these tumors in NF1 patients $^{22,43,56}$. It is important to recognize the increased, albeit low, risk of glomus tumors in NF1 patients because surgical removal of the tumor eliminates the pain.

Melanoma-The first report of concurrent NF1 and melanoma dates to the $1930 \mathrm{~s}^{59}$. Its relationship to NF1 is controversial; a variety of reports have been published in cutaneous 60 , 61 and extracutaneous ${ }^{62}$ melanoma, but no true incidence has been established. Frequencies vary between $0.1 \%$ and $5.4 \%{ }^{41}$. This association is not completely implausible, however, given the aberrations of the melanocyte in NF1. One review examined 11 cases of cutaneous melanoma in NF1 patients and found that, when compared against controls, patients were 
predominantly female, younger in age, and had a higher Breslow thickness of their lesions ${ }^{63}$. De Schepper et al noted that this is consistent with reports of ocular melanoma and hypothesized that the increased lesional thickness might be due to confusion with the multitude of other pigmented lesions in $\mathrm{NF}^{41}$.

Nevus Anemicus-Nevus anemicus is congenital, hypopigmented lesion found most often on the trunk. The pallor of these lesions is due to increased sensitivity of blood vessels to cathecholamines ${ }^{64,65}$. Most reports of the association of this finding and NF1 appear anecdotal as there is scant literature exploring this relationship. In 1969, Fleisher and Zeligmann performed experiments on nevus anemicae of patients with NF1 but the association was not explored. In their paper on NDH, Norris et al. drew comparisons to the similarity of diminished vascular reactivity of NDH and nevus anemicus but the underlying pathophysiologic mechanisms are distinct ${ }^{66}$. It is uncertain whether the finding of nevus anemicus in NF1 is coincidental since no studies - to our knowledge - have attempted to establish a correlation.

Pruritus-Another common manifestation in NF1 is pruritus. Generally it is a widespread cutaneous phenomenon but, anecdotally, some patients are able to relate that certain tumors itch more than others. The pathogenesis of this finding is uncertain but may be related to the increased number of mast cells that are found in neurofibromas. These mast cells undergo rapid growth in these tumors and, consequently, release histamine, a substance known to cause itching ${ }^{5}$. Localized pruritus can also be a clue to the presence of an underlying spinal cord or central nervous tumor ${ }^{67}$.

\section{Non-Cutaneous Manifestations}

Neurofibromatosis type 1 has the ability to affect nearly every organ system. While this paper is focused on the cutaneous manifestations, consideration must also be given to findings which the dermatologist may note on physical examination or gather from history so that appropriate steps may be taken. A summary of these findings is provided in Table II.

\section{Orthopedic}

Bony abnormalities in NF1 are variable and include scoliosis, sphenoid wing or long bone dysplasia, and more recently noted osteopenia/osteoporosis ${ }^{68}$. The underlying pathogenic mechanisms are not fully understood but experimental evidence suggests that osteoblasts (mediators of bone construction) are deficient and their counterparts the osteoclasts have increased survival leading to increased degradation of bony tissue ${ }^{69}$.

Scoliosis-Scoliosis (lateral curvature of the spine) is the most common orthopedic finding in NF1, occurring in up to $10 \%$ of patients ${ }^{49}$, usually manifesting by age $10^{16}$. The pathogenesis of this finding in NF1 is unknown but may be related to osteopenia and subsequent dysplastic bony elements ${ }^{69}$. Management varies depending on the degree of curvature, location, rate of progression, and age ${ }^{5}$. The dermatologist's role is limited, but periodic screening of the young NF1 patient is simple and painless. If evidence of scoliosis is found, referral to orthopedics is warranted.

Dysplasia of a Long Bone-Dysplasia of a long bone is another common manifestation of NF1, occurring in nearly $14 \%$ and are usually evident within the first year of life $\mathrm{e}^{25}$. This finding is particularly relevant to dermatology, as young patients come to the clinic for evaluation of "birthmarks" prior to the age of 1 and can be easily screened for this manifestation. The most commonly affected bone is the tibia, which will bow in an anterolateral direction. Coupled with the appropriate number and size of CALMs, this orthopedic manifestation is sufficient to make the diagnosis of NF1. Other findings may include overgrowth of a limb or 
congenital pseudoarthrosis (usually of the tibia), in which a fracture heals abnormally. Recently, loss of heterozygosity of the NFl gene was demonstrated in osseous tissue from two patients with tibial pseudoarthrosis suggesting this mutation has a role in the pathogenesis of these skeletal dysplasias ${ }^{70}$. Again, the dermatologist's role is limited but recognition of any of these findings will lead to appropriate management by an orthopedic specialist.

Other-Other features include short stature, relative macrocephaly, and a prominent forehead and brow. Anywhere from $29-45 \%$ of patients with NF1 have a head circumference greater than or equal to two standard deviations above the mean for sex and age $39,49,71$.

\section{Neurologic/Psychiatric}

Learning Disabilities \& Attention-Deficit Hyperactivity Disorder (ADHD)—In the broadest sense, learning disabilities occur in nearly half of all NF1 patients and are a chief concern of parents. No consistent profile of the specific deficiencies in NF1 exists but an extensive review in 2006 found that patients have academic deficiencies, particularly in math and reading, slightly lower intelligence quotients (IQs), and a high preponderance of $\mathrm{ADHD}^{72}$. These issues are of particular interest to the pediatric practitioner, as early intervention to address these concerns may lead to improved outcomes later in life.

A relationship between unidentified bright objects (UBOs) and cognitive function has been proposed. UBOs are seen in up to $80 \%$ of patients with $\mathrm{NF}^{73}$. These hyperintense areas noted on magnetic resonance imaging (MRI) are of uncertain clinical significance; studies attempting to correlate them to cognition have had mixed results but there is some evidence that the specific location (i.e., the thalamus) correlates to measured cognitive performance ${ }^{74,75}$. Utilizing MRI to screen for the presence of UBOs is not recommended, since they are neither diagnostic nor helpful in management. Regardless, children should be assessed for developmental milestone delays, learning disabilities, and school performance and appropriate resources such as neurology and/or neuropsychology should be utilized.

\section{Ophthalmologic}

The two most common problems in this category are not readily apparent in clinic to the dermatologist but are worth mention.

Lisch Nodules-Lisch nodules are small, dome-shaped hyperpigmented macules of the iris that cause no impairment of vision. They are a common finding (by age 6,15-20\% have them, 95\% of adults have them) and are included as one of the cardinal NIH diagnostic criteria $^{77-80}$. Visualization requires slit-lamp examination by experienced practitioners. For patients or family members in whom the diagnosis of NF1 is uncertain, referral for a complete eye examination is necessary.

Optic Glioma-The optic glioma is a tumor of the optic nerve and is present in $15-20 \%$ of patients with $\mathrm{NF} 1^{81,82}$. It is a slow-growing tumor and can present clinically with proptosis, decreased visual acuity, or precocious puberty (the latter most commonly after age 6); accelerated linear growth is evidence of early puberty, thus necessitating the use of growth charts in NF1 patients ${ }^{83}$. Symptomatic optic gliomas typically present prior to age 6 , with most children being diagnosed with an optic glioma by age $3^{25,81-82}$.

There is considerable controversy over the diagnosis and management and the pros and cons of the various approaches will not be debated here. It is important to the dermatologist who makes the diagnosis in a child to understand how an optic glioma may manifest and that children under the age of 8 should undergo annual evaluation by a skilled ophthalmologist or neuroophthalmologist. Less strong (but still graded as "good") evidence suggests that 
ophthalmologic evaluation should be continued every 2 years until the age of $18^{83}$. According to this same review there is no strong evidence that routine screening with neuroimaging (MRI) in the asymptomatic individual is of benefit. However, if a reliable eye examination cannot be performed, imaging may be appropriate ${ }^{83}$.

\section{Management \& Future Directions}

The dermatologist has a primary role in recognizing and differentiating NF1 from other conditions based on careful skin examination, making appropriate referrals once the diagnosis is made, and managing symptomatic or disfiguring cutaneous neurofibromas. Currently, neurofibromas are amenable only to surgical removal. Symptomatic (i.e., painful, bleeding) neurofibromas are most commonly removed but, depending on the community, this may not be handled by dermatology. Several studies have looked or are looking at testing various agents specifically directed at the plexiform neurofibroma ${ }^{84-86}$. Clinical trials with a variety of pharmacological agents are ongoing for neurofibromas, primarily progressive or disabling plexiform neurofibromas, and an updated list of trials is available at www.clinicaltrials.gov. One of these agents, sirolimus, targets mTOR (a known regulator of cell growth in the nervous system) and is the focus of a multicenter trial for plexiform neurofibromas. Of note, this same drug has shown promise in the treatment of several tumor manifestations of tuberous sclerosis ${ }^{87,88}$. Another pharmacologic agent, imatinib mesylate, was shown to reduce the size of a plexiform neurofibroma compromising the airway of a 3-year old girl; a Phase 2 clinical trial is currently underway. Imatinib inhibits stem cell factor's growth-potentiating effects by interfering with c-kit receptor activity ${ }^{89}$.

Pigmentary disturbances are generally not treated beyond the recommendation that patients wear sunscreen. Café-au-lait macules (CALMs) will darken in response to sunlight and tend to fade with time and become less noticeable. While not often located on the face, CALMs may be amenable to various cover-up products as well. A study with 8 NF1 patients used the combination of intense pulsed-radio frequency (IPL-RF) and topical vitamin $\mathrm{D}_{3}$ to treat both freckling and CALMs. Some improvement was noted, primarily in freckling, and no repigmentation of the lesions occurred for at least 6 months $^{90}$. In another study, the same group found that topical vitamin $\mathrm{D}_{3}$ analogues had measurable clinical and histological effects: there was notable lightening of the lesions and an increase in melanin incontinence ${ }^{91}$. This was a small study, however, and no large-scale, double-blinded studies have been performed to our knowledge. Other studies have examined the effects of laser on pigmented lesions in the general population but will not be discussed in detail here.

A relationship of vitamin D and neurofibromatosis type 1 has been proposed. Nakayama et al examined the response of xenograft neurofibroma tissue to a vitamin $\mathrm{D}_{3}$ analogue and found decreased cell density when compared against those treated with growth promoting agents ${ }^{92}$. Lammert et al. investigated the relationship of serum $25-\mathrm{OH}$ vitamin D concentrations in patients with NF1 and found a statistically-significant inverse relationship between the number of dermal neurofibromas and serum levels of this hormone ${ }^{93}$.

Recently, improved cognition in NF1 was reported in mice following treatment with lovastatin, an HMG-CoA reductase inhibitor that also inhibits Ras ${ }^{94}$. A large, randomized double-blind placebo-controlled trial failed to show any significant improvement after 3 months of treatment with simvastatin (another HMG-CoA reductase inhibitor) in the cognitive abilities of children with NF1, however. This is still an ongoing area of investigation ${ }^{95}$.

\section{Summary}

Neurofibromatosis type 1 is a multisystem disorder requiring management by multiple disciplines, often coordinated through a primary care physician or a geneticist. The 
dermatologist has a role not only in the diagnosis of NF1 and differentiating it from other similar disorders but also in the recognition of rare but associated skin manifestations. Genetic testing has increased our ability to make the diagnosis in uncertain cases but has not allowed us to predict a particular patient's natural history based on the mutation. Further research into genotype-phenotype correlations is needed before such predictions can be made. There is a paucity of available medical treatments but ongoing trials hold promise in treating both the cutaneous and non-cutaneous manifestations of NF1.

\section{Acknowledgments}

Funding Sources: None

\section{Abbreviations/Acronyms Used in this Text}

NF1

neurofibromatosis type 1

DNA

deoxyribonucleic acid

GAP

guanosine triphosphatase activate protein

NIH

National Institutes of Health

FISH

fluorescent in situ hybridization

RT-PCR

reverse transcriptase polymerase chain reaction

MPNST

malignant peripheral nerve sheath tumor

RAS-MAPK

Ras mitogen-activated protein kinase

FCALS

familial café-au-lait spots

CALM

café-au-lait macule

BRM

blue-red macule

PAM

pseudoatrophic macule

PN

plexiform neurofibroma

JXG

juvenile xanthogranuloma

JMML

juvenile myelomonocytic leukemia 


\section{ADHD}

attention deficit hyperactivity disorder

UBO

unidentified bright object

MRI

magnetic resonance imaging

IPL-RF

intense pulsed-radio frequency

\section{References}

1. Crowe, FW.; Schull, WJ.; Neel, JV. A Clinical, Pathologicala and Genetic Study of Multiple Neurofibromatosis. Springfield, IL: Charles C Thomas; 1956.

2. Riccardi VM. Neurofibromatosis: clinical heterogeneity. Curr Probl Cancer 1982;7:1-34. [PubMed: 6816509]

3. Viskochil D, Buchberg AM, Xu G, Cawthon RM, Stevens J, Wolff RK, et al. Deletions and a translocation interrupt a cloned gene at the neurofibromatosis type 1 locus. Cell 1990;62:187-92. [PubMed: 1694727]

4. Brems H, Chmara M, Sahbatou M, Denayer E, Taniguchi K, Kato R, et al. Germline loss-of-function mutations in SPRED1 cause a neurofibromatosis 1-like phenotype. Nat Genet 2007;39:1120-6. [PubMed: 17704776]

5. Korf, BR.; Rubenstein, AE. Neurofibromatosis: A Handbook for Patients, Families, and Health Care Professionals. Vol. 2nd. New York: Thieme; 2005.

6. Riccardi VM, Lewis RA. Penetrance of von Recklinghausen neurofibromatosis: a distinction between predecessors and descendants. Am J Hum Genet 1998;42:284-9. [PubMed: 3124613]

7. Theos A, Korf BR. Pathophysiology of Neurofibromatosis Type 1. Ann Intern Med 2006;144:842-9. [PubMed: 16754926]

8. Messiaen LM, Callens T, Mortier G, Beysen D, Vandenbroucke I, Van Roy N, et al. Exhaustive mutation analysis of the NF1 gene allows identification of $95 \%$ of mutations and reveals a high frequency of unusual splicing defects. Hum Mutat 2000;15:541-55. [PubMed: 10862084]

9. Ars E, Kruyer H, Morell M, Pros E, Serra E, Ravella A, et al. Recurrent mutations in the NF1 gene are common among neurofibromatosis type 1 patients. J Med Genet 2003;40:e82. [PubMed: 12807981]

10. Heim RA, Kam-Morgan LNW, Binnie CG, Corns DD, Cayouette MC, Farber RA, et al. Distribution of 13 truncating mutation in the neurofibromatosis 1 gene. Hum Mol Genet 1995;4:975-81. [PubMed: 7655472]

11. Ruggieri M, Huson SM. The clinical and diagnostic implications of mosaicism in the neurofibromatoses. Neurology 2001;56:1433-43. [PubMed: 11409413]

12. Lazaro C, Ravella A, Gaona A, Volpini V, Estivill X. Neurofibromatosis type 1 due to germ-line mosaicism in a clinically normal father. N Engl J Med 1994;331:1403-7. [PubMed: 7969279]

13. Consoli C, Moss C, Green S, Balderson D, Cooper DN, Upadhyaya M. Gonosomal mosaicism for a nonsense mutation (R1947X) in the NF1 gene in segmental neurofibromatosis type 1. J Invest Dermatol 2005;125:463-6. [PubMed: 16117786]

14. Boltshauser E, Stocker H, Machler M. Neurofibromatosis type 1 in a child of a parent with segmental neurofibromatosis (NF-5). Neurofibromatosis 1989;2:244-5. [PubMed: 2517819]

15. Theiler R, Stocker H, Boltshauser E. Zur Klassierung atypishcer Neurofibromatose-Formen. Schweiz Med Wochenschr 1991;121:446-55. [PubMed: 1903213]

16. Rubenstein, AE.; Korf, BR. Neurofibromatosis: A Handbook for Patients, Families, and Health Care Professionals. Vol. 1st. New York: Thieme; 1990.

17. Moss C, Green SH. What is segmental neurofibromatosis? Br J Dermatol 1994;130:106-10. [PubMed: 8305298] 
18. Segal R. Segmental neurofibromatosis of the sciatic nerve: case report. Neurosurgery 1993;33:948. [PubMed: 8264903]

19. Uhlin SR. Segmental neurofibromatosis. South Med J 1980;73:526-7. [PubMed: 6768137]

20. Stocker KM, Baizer L, Coston T, Sherman L, Ciment G. Regulated Expression of Neurofibromin in Migrating Neural Crest Cells of Avian Embryos. J Neurobiol 1995;27:535-52. [PubMed: 7561832]

21. Maertens O, De Schepper S, Vandesompele J, Brehms H, Heyns I, Janssens S, et al. Molecular Dissection of Isolated Disease Features in Mosaic Neurofibromatosis Type 1. Am J Hum Genet 2007;81:243-51. [PubMed: 17668375]

22. De Schepper S, Maertens O, Callens T, Naeyaert JM, Lambert J, Messiaen L. Somatic Mutation Analysis in NF1 Café-au-lait Spots Reveals Two NF1 Hits in the Melanocytes. J Invest Dermatol 2008;128:1050-3. [PubMed: 17914445]

23. Wu J, Williams JP, Rizvi TA, Kordich JJ, Witte D, Meijer D, et al. Plexiform and dermal neurofibromas and pigmentation are caused by Nf1 loss in desert hedgehog-expressing cells. Cancer Cell 2008;13:105-16. [PubMed: 18242511]

24. Gutmann DH, Aylsworth A, Carey JC, Korf B, Marks J, Pyeritz RE, et al. The diagnostic evaluation and multidisciplinary management of neurofibromatosis 1 and neurofibromatosis 2. JAMA 1997;278:51-7. [PubMed: 9207339]

25. DeBella K, Szudek J, Friedman JM. Use of the National Institutes of Health criteria for diagnosis of neurofibromatosis 1 in children. Pediatrics 2000;105:608-14. [PubMed: 10699117]

26. Kluwe L, Siebert R, Gesk S, Friedrich RE, Tinschert S, Kehrer-Sawatzki H, et al. Screening 500 unselected neurofibromatosis 1 patients for deletions of the NF1 gene. Hum Mutat 2004;23:111-6. [PubMed: 14722914]

27. Leppig KA, Kaplan P, Viskochil DWeaver M, Ortenberg J, Stephens K. Familial neurofibromatosis 1 microdeletions: cosegregation with distinct facial phenotype and early onset of cutaneous neurofibromata. Am J Med Genet 1997;73:197-204. [PubMed: 9409873]

28. De Raedt T, Brems H, Wolkenstein P, Vidaud D, Pilotti S, Perrone F, et al. Elevated risk for MPNST in NF1 microdeletion patients. Am J Hum Genet 2003;72:1288-92. [PubMed: 12660952]

29. Upadhyaya M, Huson SM, Davies M, Thomas N, Chuzhanova N, Giovannini S, et al. An absence of cutaneous neurofibromas associated with a 3-bp inframe deletion in exon 17 of the NF1 gene (c. 2970-2972 delAAT): evidence of a clinically significant NF1 genotype-phenotype correlation. Am J Hum Genet 2007;80:140-51. [PubMed: 17160901]

30. Riccardi VM. Pathophysiology of neurofibromatosis: IV. Dermatologic insights into heterogeneity and pathogenesis. J Am Acad Dermatol 1980;3:157-66. [PubMed: 6774000]

31. Abeliovich D, Gelman-Kohan Z, Silverstein S, Lerer I, Chemke J, Merin S, et al. Familial cafe-aulait spots: a variant of neurofibromatosis type 1. J Med Genet 1995;32:985-6. [PubMed: 8825931]

32. Charrow J, Listernick R, Ward K. Austomal dominant multiple café-au-lait spots and neurofibromatosis-1: evidence of non-linkage. Am J Med Genet 1993;45:606-8. [PubMed: 8456833]

33. Whitehouse D. Diagnostic value of the café-au-lait spot in children. Arch Dis Child 1966;41:316319. [PubMed: 4957366]

34. Landau M, Krafchik BR. The diagnostic value of café-au-lait macules. J Am Acad Dermatol 1999;40:877-90. [PubMed: 10365918]

35. Ortonne JP, Brocard E, Floret D, Perrot H, Thivolet J. Valeur diagnostique des taches café-au-lait. Ann Dermatol Venereol 1980;107:313-27. [PubMed: 6770739]

36. De Schepper S, Boucneau J, Vander Haeghen YV, Messiaen L, Naeyaert JM, Lambert J. Café-aulait spots in neurofibromatosis type 1 and in healthy control individuals: hyperpigmentation of a different kind? Arch Dermatol Res 2006;297:439-49. [PubMed: 16479403]

37. Kaufmann D, Krone W, Hochsattel R, Martin R. A cell culture study on melanocytes from patients with neurofibromatosis-1. Arch Dermatol Res 1989;281:510-3. [PubMed: 2514626]

38. Obringer AC, Meadows AT, Zackai EH. The diagnosis of neurofibromatosis-1 in the child under the age of 6 years. Am J Dis Child 1989;143:717-9. [PubMed: 2499182]

39. Huson SM, Harper PS, Compston DA. Von Recklinghausen neurofibromatosis: a clinical and population study in south-east Wales. Brain 1988;111:1355-81. [PubMed: 3145091] 
40. Riccardi VM. Von Recklinghausen neurofibromatosis. N Engl J Med 1981;305:1617-27. [PubMed: 6796886]

41. De Schepper S, Boucneau J, Lambert J, Messiaen L, Naeyaert JM. Pigment cell-related manifestations in neurofibromatosis type 1: an overview. Pigment Cell Res 2005;18:13-24. [PubMed: 15649148]

42. Page PZ, Page GP, Ecosse E, Korf BR, Leplege A, Wolkenstein P. Impact of neurofibromatosis 1 on Quality of Life: a cross-sectional study of 176 American cases. Am J Med Genet A 2006;140:18938. [PubMed: 16906549]

43. Maertens O, Brems H, Vandesompele J, De Raedt T, Heyns I, Rosenbaum T, et al. Comprehensive NF1 screening on cultured Schwann cells from neurofibromas. Hum Mutat 2006;27:1030-40. [PubMed: 16941471]

44. Westerhof W, Konrad K. Blue-red macules and pseudoatrophic macules: additional cutaneous signs in neurofibromatosis. Arch Dermatol 1982;118:577-81. [PubMed: 6808930]

45. Zeller J, Wechsler J, Revuz J, Wolkenstein P. Blue-red macules and pseudoatrophic macules in neurofibromatosis 1. Ann Dermatol Venerol 2002;129:180-1.

46. Piqué E, Olivares M, Fariña MC, Martin L, Sarasa JL, Campos JM, et al. Pseudoatrophic Macules: A Variant of Neurofibroma. Cutis 1996;57:100-2. [PubMed: 8646852]

47. Norris JF, Smith AG, Fletcher PJ, Marshall TL, Hand MJ. Neurofibromatous dermal hypoplasia: a clinical, pharmacological and ultrastructural study. Br J Dermatol 1985;112:435-41. [PubMed: 3922394]

48. Evans DG, Baser ME, McGaughran J, Sharif S, Howard E, Moran A. Malignant peripheral nerve sheath tumors in neurofibromatosis 1. J Med Genet 2002;39:311-314. [PubMed: 12011145]

49. Friedman, JM.; Gutmann, DH.; MacCollin, M.; Riccardi, VM., editors. Neurofibromatosis: Phenotype, Natural History, and Pathogenesis. Vol. 3rd. Baltimore, MD: Johns Hopkins University Press; 1999.

50. Morier P, Merot Y, Paccaud D, Beck D, Frenk E. Juvenile chronic granulocytic leukemia, juvenile xanthogranulomas, and neurofibromatosis. Case report and review of the literature. J Am Acad Dermatol 1990;22:962-5. [PubMed: 2110580]

51. Zvulunov A, Barak Y, Metzker A. Juvenile xanthogranuloma, neurofibromatosis, and juvenile chronic myelogenous leukemia. World statistical analysis. Arch Dermatol 1995;131:904-8. [PubMed: 7632061]

52. Gutmann DH, Gurney JG, Shannon KM. Juvenile xanthogranuloma, neurofibromatosis 1, and juvenile chronic myeloid leukemia. Arch Dermatol 1996;132:1390. [PubMed: 8915325]

53. Burgdorf WHC, Zelger B. JXG, NF1, and JMML: Alphabet Soup or a Clinical Issue? Pediatr Dermatol 2004;21:174-6. [PubMed: 15078363]

54. Cooper PH, Frierson HF, Kayne AL, Sabio H. Association of juvenile xanthogranuloma with juvenile myeloid leukemia. Arch Dermatol 1984;120:371-5. [PubMed: 6422862]

55. North, PE.; Kincannon, J. Vascular Neoplasms and Neoplastic-like Proliferations. In: Bolognia, JL.; Jorizzo, JL.; Rapini, RP., editors. Dermatology. Mosby; 2008. p. 1790-2.

56. De Smet L, Sciot R, Legius E. Multifocal glomus tumours of the fingers in two patients with neurofibromatosis type 1. BMJ 2002;39:e45.

57. Okada O, Demitsu T, Manabe M, Yoneda K. A case of multiple subungual glomus tumors associated with neurofibromatosis type 1. J Dermatol 1999;26:418-9.

58. Sawada S, Honda M, Kamide R, Niimura M1. Three cases of subungual glomus tumors with von Recklinghausen neurofibromatosis. J Am Acad Dermatol 1995;32:277-8. [PubMed: 7829715]

59. Bjorneboe M. Melanosarcoma of brain, pigmented naevi of the skin and cutaneous neurofibromatosis. Frankf Z Pathol 1934;47:363-73.

60. Gallino G, Belli F, Tragnia G, Ferro F, Massone PP, Ditto A, et al. Association between cutaneous melanoma and neurofibromatosis type 1: analysis of three clinical cases and review of the literature. Tumori 2000;86:70-4. [PubMed: 10778770]

61. Salvi PF, Lombardi A, Puzzovio A, Stagnitti F, Tisba M, Gaudinieri A, et al. Cutaneous melanoma with neurofibromatosis type 1: a rare association? A case report and review of the literature. Ann Ital Chir 2004;75:91-5. [PubMed: 15283396] 
62. Honavar SG, Singh AD, Shields CL, Shields JA, Eagle RC Jr. Iris melanoma in a patient with neurofibromatosis. Surv Ophthalmol 2000;45:231-6. [PubMed: 11094247]

63. Guillot B, Dalac S, Delaunay M, Baccard M, Chevrant-Breton J, Dereure O, et al. Cutaneous malignant melanoma and neurofibromatosis type 1. Melanoma Res 2004;14:159-63. [PubMed: 15057048]

64. Mountcastle EA, Diestelmeier MR, Lupton GP. Nevus anemicus. J Am Acad Dermatol 1986;14:62832. [PubMed: 3007588]

65. Greaves MW, Birkett D, Johnson C. Nevus anemicus: a unique catechoamine-dependent nevus. Arch Dermatol 1970;102:172-6. [PubMed: 5430312]

66. Fleisher TL, Zeligman I. Nevus anemicus. Arch Dermatol 1969;100(6):750-5. [PubMed: 4188989]

67. Johnson RE, Kanigsberg ND, Jimenez CL. Localized pruritus: a presenting symptom of a spinal cord tumor in a child with features of neurofibromatosis. J Am Acad Dermatol 2000;43:958-61. [PubMed: 11044833]

68. Lammert M, Kappler M, Mautner VF, Lammert K, Storkel S, Friedman JM, et al. Decreased bone mineral density in patients with neurofibromatosis 1 . Osteoporos Int 2005;16:1161-6. [PubMed: 15988556]

69. Schindeler A, Little DG. Recent insights into bone development, homeostasis, and repair in type 1 neurofibromatosis (NF1). Bone 2008;42:616-22. [PubMed: 18248783]

70. Stevenson DA, Zhou H, Ashrafi S, Messiaen LM, Carey JC, D'Astous JL, et al. Double inactivation of NF1 in tibial pseudoarthrosis. Am J Hum Genet 2006;79:143-8. [PubMed: 16773574]

71. Carey JC, Laub JM, Hall BD. Penetrance and variabilitiy in neurofibromatosis: a genetic study of 60 families. Birth Defects Orig Artic Ser 1979;15:271-81. [PubMed: 118780]

72. Levine TM, Materek A, Abel J, O'Donnell M, Cutting LE. Cognitive profile of neurofibromatosis type 1. Semin Pediatr Neurol 2006;13:8-20. [PubMed: 16818171]

73. North K. Neurofibromatosis type 1. AmJ Med Genet 2000;97:119-27. [PubMed: 11180219]

74. Goh WH, Khong PL, Leung CS, Wong VC. T2-weighted hyperintensities (unidentified bright objects) in children with neurofibromatosis 1: their impact on cognitive function. J Child Neurol 2004;19:8538. [PubMed: 15658789]

75. Moore BD, Slopis JM, Schomer D, Jackson EF, Levy BM. Neuropsychological significance of areas of high signal intensity on brain MRIs of children with neurofibromatosis. Neurology 1996;46:16608. [PubMed: 8649566]

76. Lewis RA, Riccardi VM. Von Recklinghausen neurofibromatosis: incidence of iris hamartomas. Ophthalmology 1981;88:348-54. [PubMed: 6789269]

77. Huson SM, Jones D, Beck L. Ophthalmologic manifestations of neurofibromatosis. Br J Ophthalmol 71:235-8. [PubMed: 3103673]198

78. Zehavi C, Romano A, Goodman RM. Iris (Lisch) nodules in neurofibromatosis. Clin Genet 1986;29:51-5. [PubMed: 3081287]

79. Flueler U, Boltshauser E, Kilchhofer A. Iris hamartomata as diagnostic criterion in neurofibromatosis. Neuropediatrics 1986;17:183-5. [PubMed: 3100979]

80. Riccardi, VM. Neurofibromatosis: Phenotype, Natural History, and Pathogenesis. Vol. 2nd. Baltimore, MD: Johns Hopkins University Press; 1992.

81. Listernick R, Charrow J, Greenwald MJ, Esterly NB. Optic gliomas in children with neurofibromatosis type 1. J Pediatr 1989;114:788-92. [PubMed: 2497236]

82. Listernick R, Charrow J, Greenwald M, Mets M. Natural history of optic pathway tumors in children with neurofibromatosis type 1: a longitudinal study. J Pediatr 1994;125:63-6. [PubMed: 8021787]

83. Listernick R, Ferner RE, Liu GT, Gutmann DH. Optic Pathway Gliomas in Neurofibromatosis-1: Controversies and Recommendations. Ann Neurol 2007;61:189-98. [PubMed: 17387725]

84. Babovic-Vuksanovic D, Widemann BC, Dombi E, Gillespie A, Wolters PL, Toledo-Tamula MA, et al. Phase I trial of pirfenidone in children with neurofibromatosis 1 and plexiform neurofibromas. Pediatr Neurol 2007;36:293-300. [PubMed: 17509460]

85. Babovic-Vuksanovic D, Ballman K, Michels V, McGrann P, Lindor N, King B, et al. Phase II trial of pirfenidone in adults with neurofibromatosis type 1. Neurology 2006;67:1860-2. [PubMed: 17035676] 
86. Widemann BC, Salzer WL, Arceci RJ, Blaney SM, Fox E, End D, et al. Phase I trial and pharmacokinetic study of the farnesyltransferase inhibitor tipifarnib in children with refractory solid tumors or neurofibromatos type I and plexiform neurofibromas. J Clin Oncol 2006;24:507-16. [PubMed: 16421428]

87. Franz DN, Leonard J, Tudor C, Chuck G, Care M, Seturaman G, et al. Rapamycin causes regression of astrocytomas in tuberous sclerosis complex. Ann Neurol 2006;59:490-8. [PubMed: 16453317]

88. Wienecke R, Fackler I, Lisenmaier U, Mayer K, Licht T, Kretzler M. Antitumoral activity of rapamycin in renal angiomyolipoma associated with tuberous sclerosis complex. Am J Kidney Dis 2006;48:e27-9. [PubMed: 16931204]

89. Yang FC, Ingram DA, Chen S, Zhu Y, Yuan J, Li X, et al. Nfl-dependent tumors require a microenvironment containing $N f 1^{+/-}$- and c-kit-dependent Bone Marrow. Cell 2008;135:437-48. [PubMed: 18984156]

90. Yoshida Y, Sato N, Furumura M, Nakayama J. Treatment of pigmented lesions of neurofibromatosis 1 with intense pulsed-radio frequency in combination with topical application of vitamin $\mathrm{D}_{3}$ ointment. J Dermatol 2007;34:227-30. [PubMed: 17352718]

91. Nakayama J, Kiryu H, Urabe K, Matsuo S, Shibata S, Koga T, et al. Vitamin D3 analogues improve café au lait spots in patients with von Recklinghausen's disease: experimental and clinical studies. Eur J Dermatol 1999;9:202-6. [PubMed: 10210785]

92. Nakayama J, Matsuo S, Rikihisa W, Hori Y. Inhibitory effect of a new vitamin D3 analogue, 22oxacalcitriol, on the growth of neurofibroma cells xenografted into nude mouse skin in vivo. Eur J Dermatol 1997;7:475-9.

93. Lammert M, Friedman JM, Roth HJ, Friedrich RE, Kluwe L, Atkins D, et al. Vitamin D deficiency associated with number of neurofibromas in neurofibromatosis 1. J Med Genet 2006;43:810-3. [PubMed: 16571643]

94. Li W, Cui Y, Kushner SA, Brown RA, Jentsch JD, Frankland PW, et al. The HMG-CoA reductase inhibitor lovastatin reverses the learning and attention deficits in a mouse model of neurofibromatosis type 1. Curr Biol 2005;15:1961-7. [PubMed: 16271875]

95. Krab LC, de Goede-Bolder A, Aarsen FK, Pluijm SM, Bouman MJ, van der Geest JN, et al. Effect of simvastatin on cognitive functioning in children with neurofibromatosis type 1: a randomized controlled trial. JAMA 2008;300:287-94. [PubMed: 18632543] 


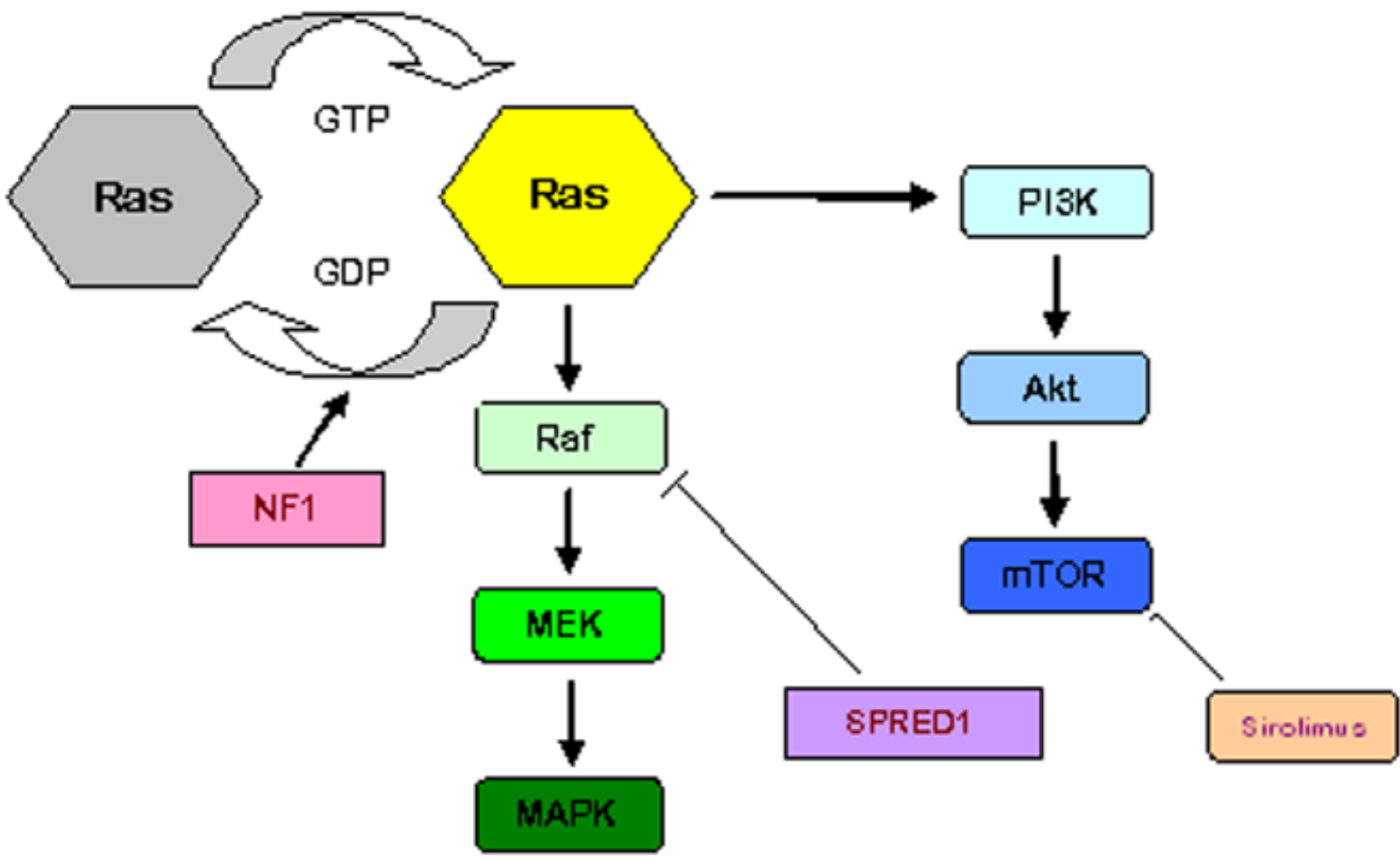

\section{MAPK = mitogen activated protein kinase ERK = extracellular signal-re gulated kinase MEK = MAPKJER K kinase PLK = phosphoinositide 3-kinase}

Figure 1. Schematic of interactions of key proteins and genes involved in the pathogenesis of NF1 The MAPK/ERK pathway is a complex series of signals and interactions involved in cell growth and proliferation. Under normal conditions, the NF1 gene product neurofibromin promotes the conversion of Ras into its inactive form, thus suppressing cell growth. In NF1, there is a loss of or diminished function of the NF1 gene and the process is left unhindered. SPRED1 inhibits Raf and is the implicated gene/protein in NF1-like syndrome. mTOR has a key role in an additional pathway leading to cell growth and proliferation. Sirolimus inhibits it by binding to an intracellular receptor, FKBP12 (not shown), the complex of which then binds directly to mTOR. 


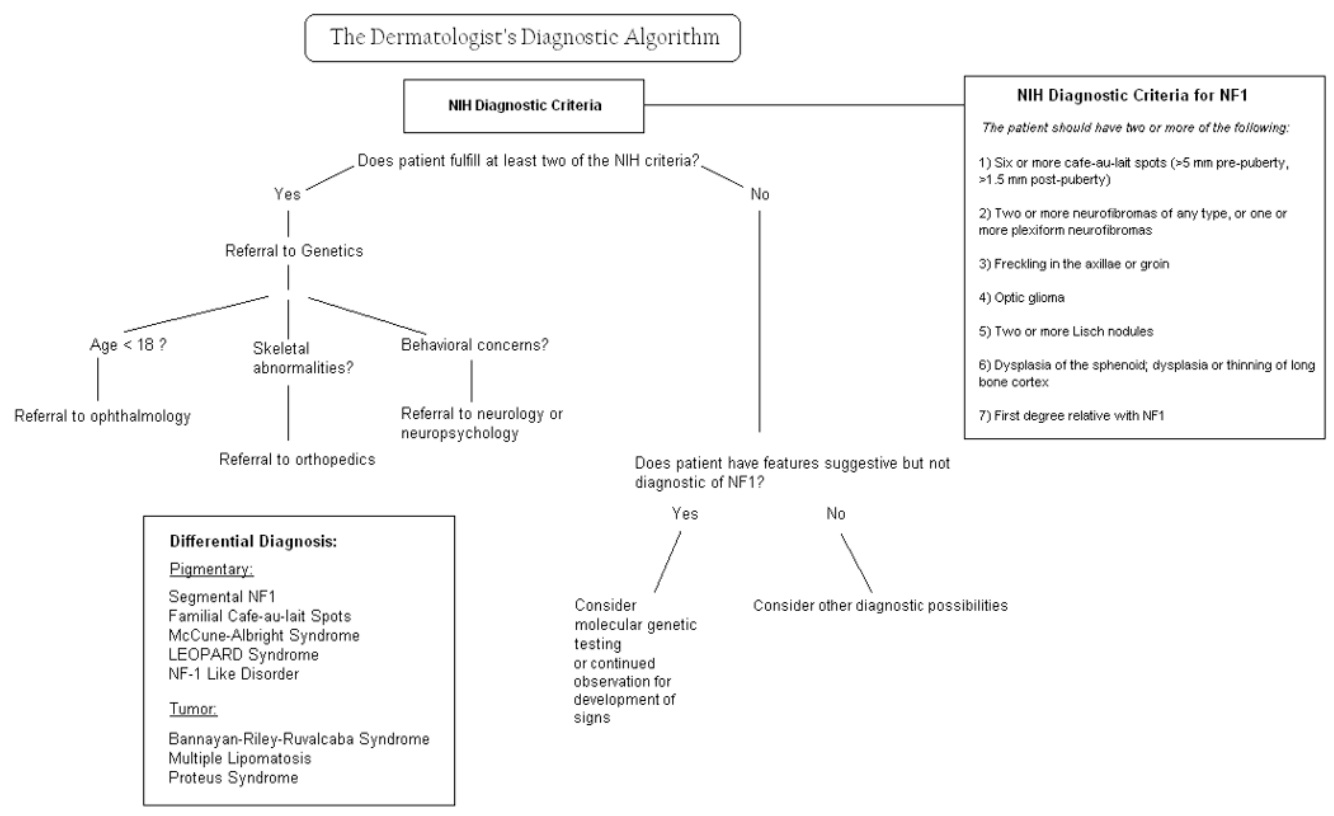

Figure 2.

J Am Acad Dermatol. Author manuscript; available in PMC 2010 July 1. 


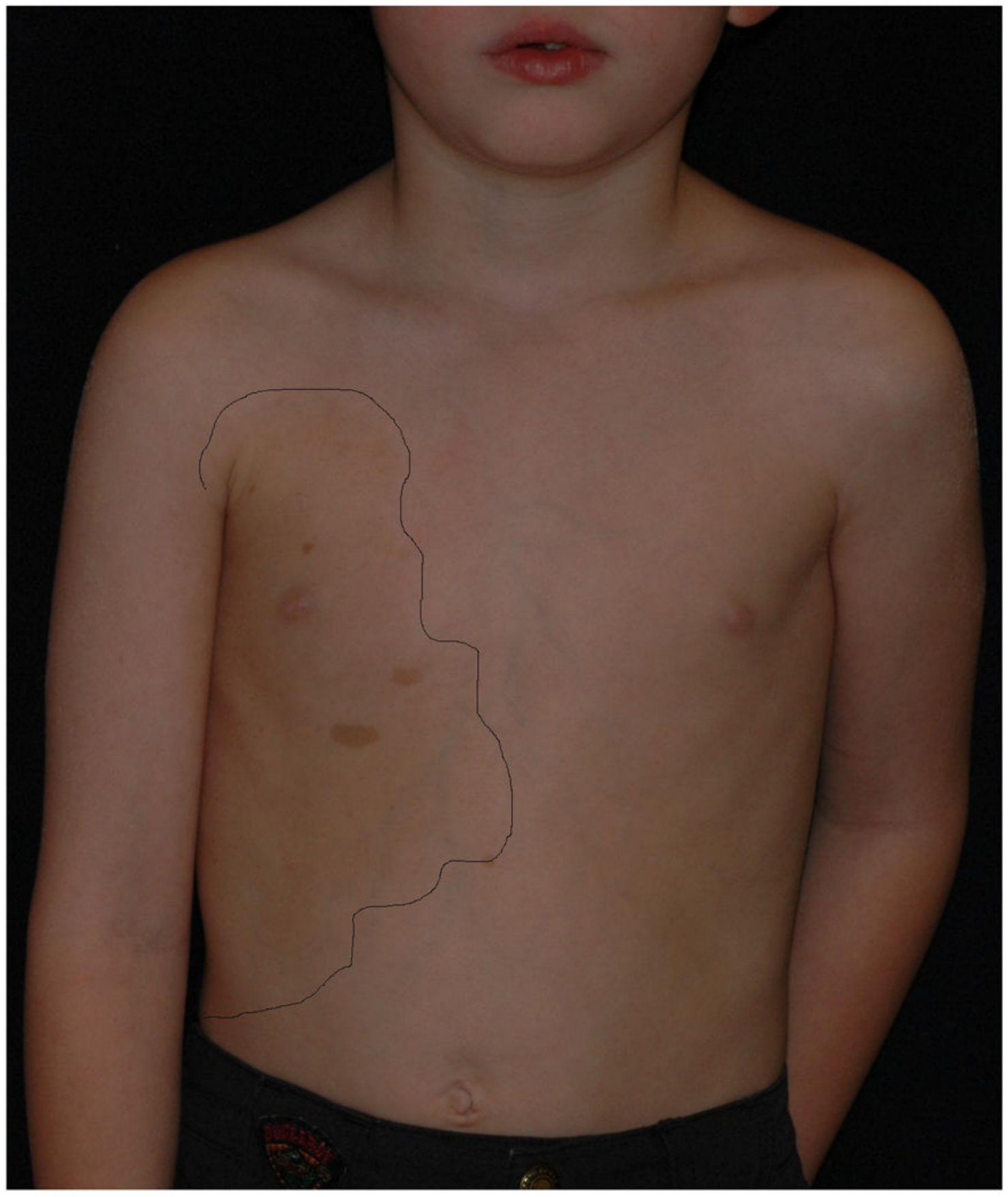




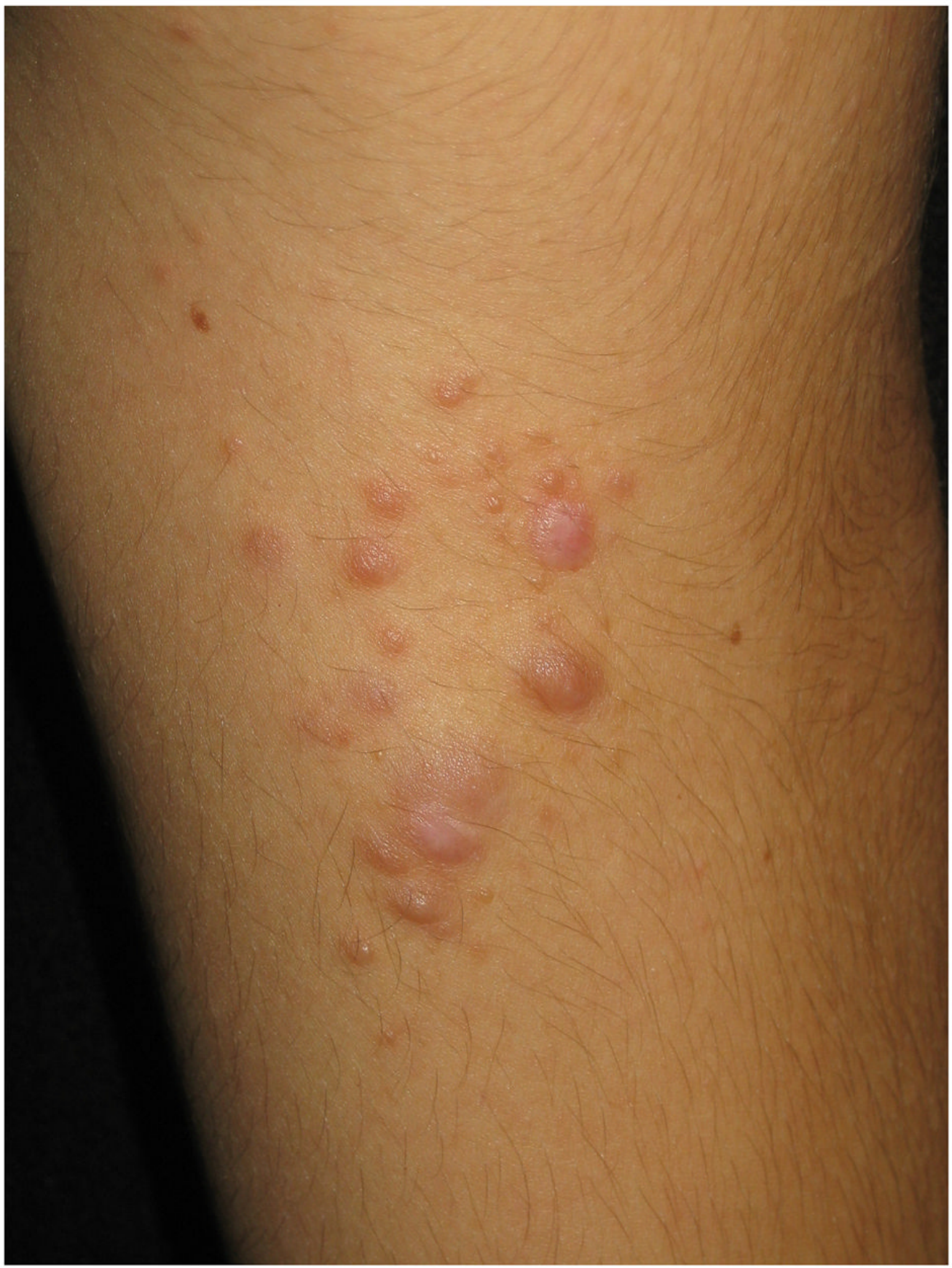

Figures 3.

a \& b. Pictures of segmental NF1 showing patients with a) pigmentary and b) tumor manifestations. 


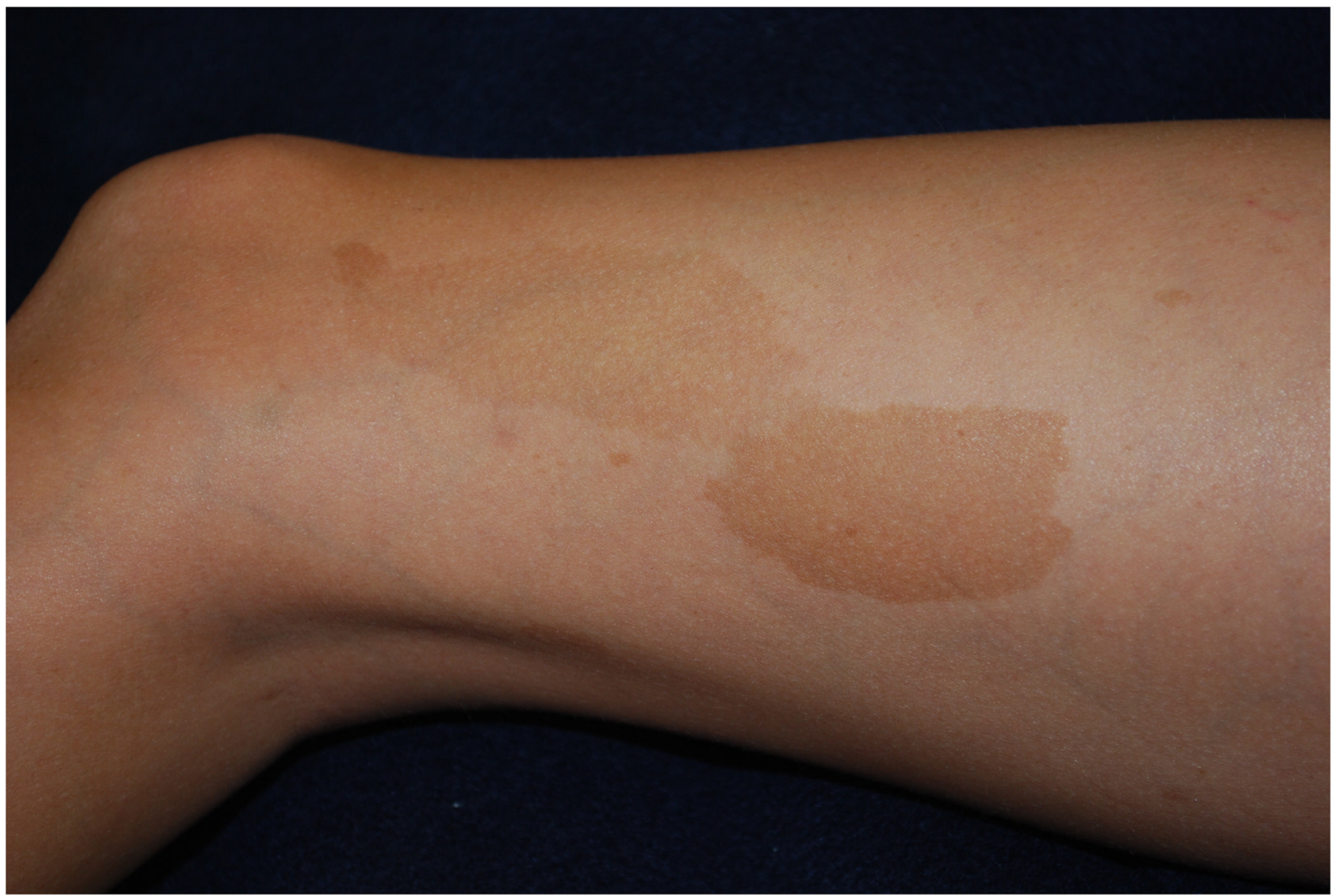

Figure 4.

Cafe-au-lait macules on the thigh of a child. 


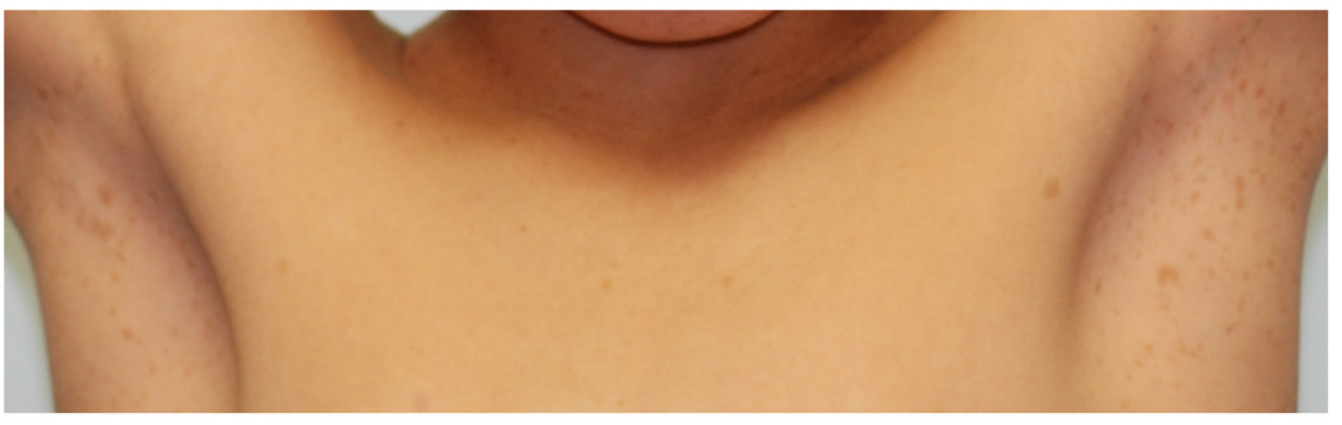

Figure 5.

Bilateral axillary freckling in a child. 

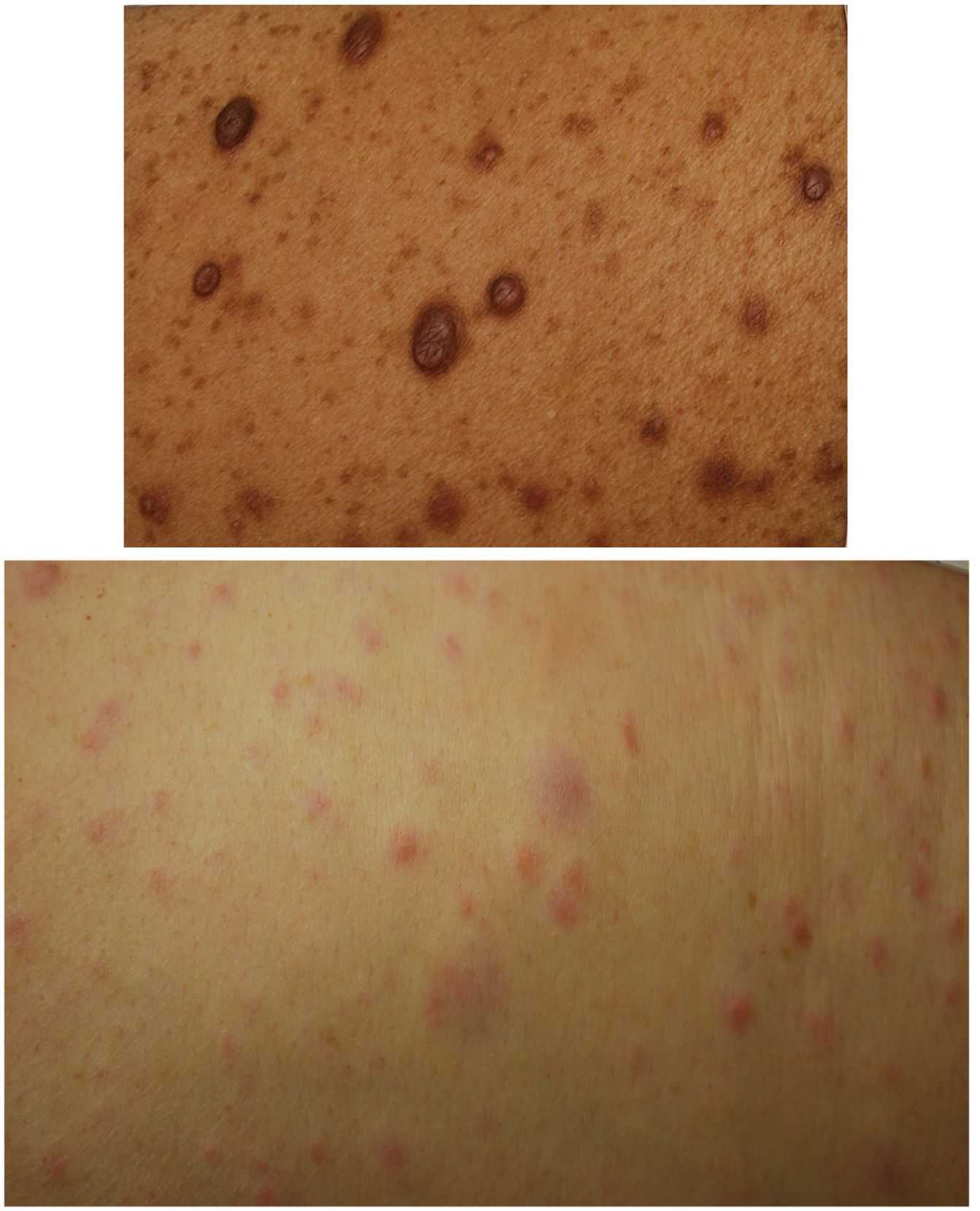

Figures 6.

a \& b. Various morphologies of cutaneous neurofibromas. 


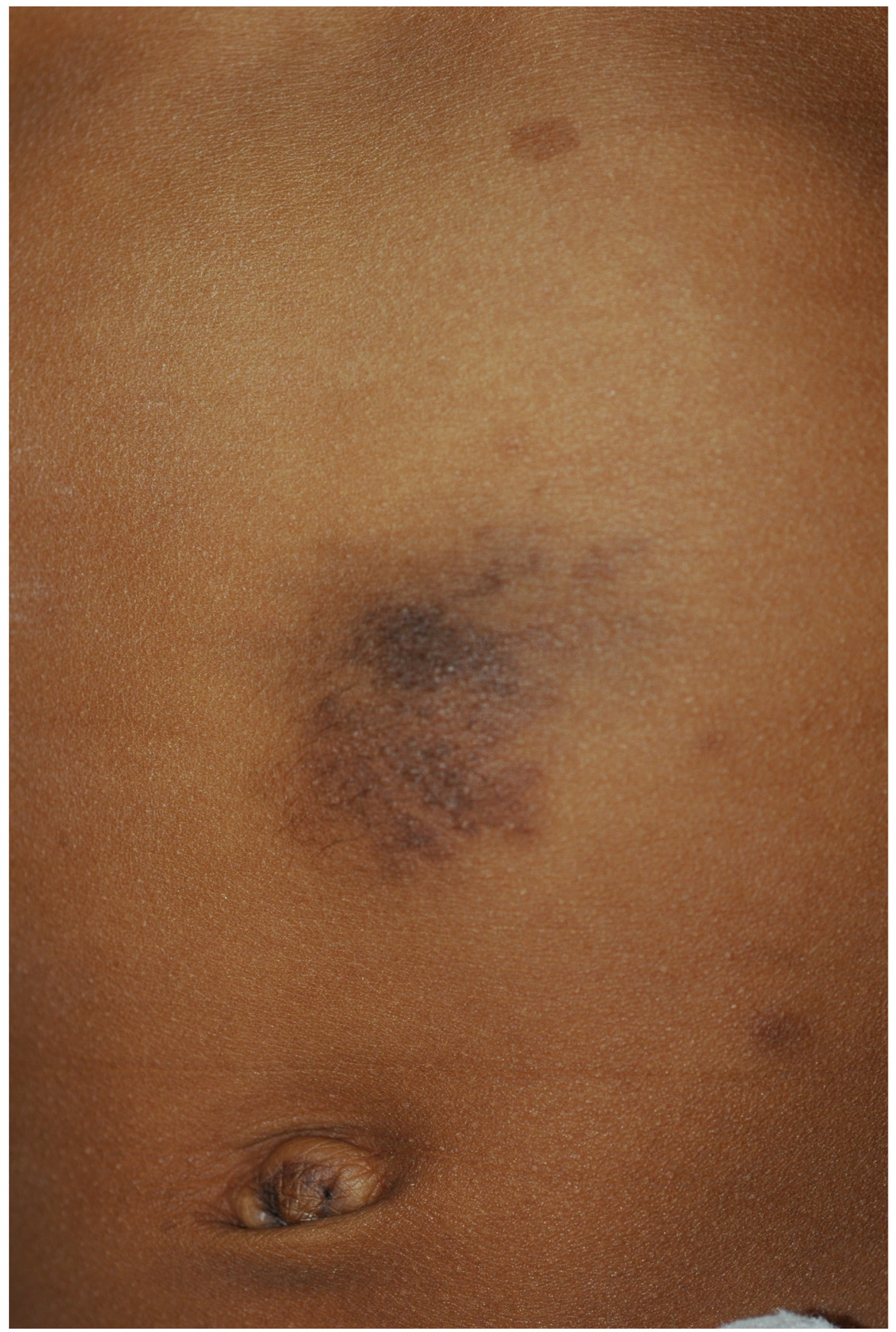

Figure 7.

Plexiform neurofibroma on the abdomen of a child. 


\section{Cutaneous Findings in NF1}

Table I

\begin{tabular}{ll}
\hline Common & Uncommon or Reported Associatior \\
\hline Café-au-lait macules $^{*}$ & Juvenile xanthogranuloma (JXG) \\
Axillary/Inguinal Freckling (Crowe's sign) & Glomus tumor \\
Neurofibromas (dermal, plexiform) & Melanoma \\
Increased base pigmentation & Blue-red macules \\
& Pseudoatrophic macules
\end{tabular}

* Diagnostic criterion for NF1 


\section{Extracutaneous Findings in NF1}

\section{Table II}

\begin{tabular}{ll}
\hline Skeletal & Cardiovascular \\
\hline Scoliosis & Hypertension \\
Dysplasia of the long bone or sphenoid ${ }^{*}$ & Vascular dysplasia \\
Macrocephaly & Endocrine \\
Prominent brow & Precocious puberty \\
Short stature & Pheochromocytoma \\
Pectus excavatum & Gastrointestinal \\
Pseudoarthrosis (esp. of tibia) & Constipation \\
Neurologic/Psychologic & Gastrointestinal stromal tumors (GIST) \\
Headaches & Associated Malignancies \\
Learning disabilities/ADHD & Juvenile myelomonocytic leukemia (JMML) \\
Astrocytoma & Malignant peripheral nerve sheath tumor (MPNST) \\
Seizures & \\
Ophthalmologic & \\
Lisch Nodules & \\
Optic Glioma & \\
\hline Diagnostic criterion for NF1 & \\
\hline & \\
\hline
\end{tabular}


Table III

Indications for Genetic Testing

Individuals at 50\% risk

Patients with a single sign

Individuals with variant disorders

Prenatal testing

Pre-implantation genetic diagnosis 